\title{
A (ultra)precarização do trabalho como condição de acesso à Previdência Social ${ }^{1} /$ The (ultra)precarisation of work as a condotion of access to Social Security
}

Laudicena Maria Pereira Barreto ${ }^{2}$

Resumo: Este ensaio discute a Lei no $12.470 / 11$, que trata sobre os contribuintes facultativos da Previdência Social, na condição de donos e donas de casa de baixa renda, com redução da alíquota de contribuição. Consideramos que a criaçáo destes novos segurados da previdência são uma conquista, especialmente para as mulheres que são donas de casa de baixa renda. Todavia, ponderamos sobre as exigências estabelecidas na lei, pois desconsideram as condiçôes reais de vida e de trabalho das mulheres das classes subalternas e pauperizadas. Estas mulheres são chefes de família e necessitam trabalhar para obter renda e sustentar as suas famílias, além de realizarem as tarefas domésticas como donas de casa. Em decorrência, levantamos a hipótese de que para se tornarem seguradas, as mulheres se submetem à (ultra)precarizaçáo do trabalho, o que torna o acesso à renda um caminho obscuro e aberto a todas as formas de trabalho precário, desumano e degradante.

Palavras-chave: proteção social; Previdência Social; trabalho; contribuintes facultativos; donas de casa de baixa renda.

1 Este ensaio é produto de reflexões construídas na disciplina Seminário de Tese 1, do Doutorado em Serviço Social da UFPE, conduzida pela Prof a Dra. Ana Elizabete Mota. A partir das discussôes expostas no trabalho final da disciplina, optamos por sistematizá-las no presente texto, como parte do objeto de estudo da nossa tese de doutorado. À professora Ana Elizabete Mota, agradecemos as contribuiçóes.

2 Assistente Social, Professora Assistente A (Dedicação Exclusiva) do Departamento de Serviço Social da UFPE. Doutoranda e mestre em Serviço Social pelo Programa de Pós-Graduação em Serviço Social (UFPE). Especialista em Políticas Públicas e Gestão de Serviços Sociais pela UFPE e Direitos Humanos pela UCB. Atuação, pesquisas e estudos na área de Serviço Social, Política Social, Seguridade Social, Previdência Social, Direitos Humanos e Gênero. 
Abstract: This essay discusses about Law 12.470/11, which deals with the voluntary contributors of Social Security, as owners and low-income housewives, with a reduction in the contribution rate. We believe that the creation of these new Social Security insurers are an achievement, especially for women who are low-income housewives. However, we considered the conditionalities established in Law 12.470 because they disregard the real conditions of life and work of women of the subaltern and impoverished classes. Especially because these women are heads of household and need to work to earn some income to support their families, as well as doing housework as housewives. As a result, we hypothesize that in order to become insured, women are submitted to (ultra) precariousness of work, which makes access to income a dark and open path to all forms of precarious, inhuman and degrading work.

Keywords: social protection; Social Security; work; optional contributors; low income housewives.

$\mathrm{D}$ iscutir os paradoxos e as contradiçóes da Lei no 12.470, que legisla sobre a contribuição facultativa ${ }^{3}$ de donos e donas de casa de baixa renda à Previdência Social, é o propósito deste texto. Seu objetivo é problematizar o que é considerado uma conquista das mulheres donas de casa de baixa renda, em face da existência de um conjunto de mediaçóes que terminam por tornar as exigências da Lei no 12.470 um mecanismo potencializador da (ultra)precarização do trabalho dessas mulheres. Para ter direito à contribuição reduzida, a legislação exige que essas donas de casa se dediquem exclusivamente às tarefas domésticas. Supomos que para se tornarem seguradas, tais mulheres se submetem à (ultra)precarização do trabalho, o que torna o acesso à renda um caminho obscuro e aberto a todas as formas de trabalho precário, desumano e degradante.

3 Contribuinte facultativo é a pessoa maior de 16 anos de idade que não exerça atividade remunerada que a enquadre como segurada obrigatório da Previdência Social. Disponível em: <www.dataprev.gov.br/serviços/cadint/definicoesBindividual.htm>. Acessado em: 11/12/2016. 
Em agosto de 2011, foi aprovada, no âmbito da Previdência Social brasileira, a Lei no $12.470,{ }^{4}$ a fim de admitir e regulamentar a contribuição facultativa previdenciária de donos e donas de casa sem renda própria que se dediquem exclusivamente ao trabalho doméstico no âmbito de sua residência, desde que pertencentes à família de baixa renda.

A Lei Orgânica da Seguridade Social já previa que donos e donas de casa pudessem contribuir com a Previdência Social, na condição de contribuintes facultativos. O que de novo apresenta a Lei de 2011, voltada para os donos e donas de casa, diferenciando-os dos demais contribuintes, é tanto a sua condição de baixa renda como a redução da alíquota de contribuição, desde que preencham os seguintes requisitos: 1. inexistência de renda pessoali; 5 . renda familiar mensal de até dois salários mínimos; 3. inscrição no Cadastro Único para Programas Sociais do Governo Federal (CadÚnico).

De acordo com os dados de Cordeiro (2014, p. 345), em 2013, a Previdência Social já contava com mais de 560.000 contribuintes facultativos, donos e donas de casa, na condição de baixa renda, sendo 16.650 homens e 552.524 mulheres. Além de revelar o volume significativo destes contribuintes que surgem em 2011, constata-se que são majoritariamente as mulheres, as contribuintes que se dedicariam exclusivamente ao trabalho doméstico - ou afazeres domésticos, como posto na letra da lei. O Estado brasileiro, ao ampliar o acesso à Previdência Social para mulheres e homens de baixa renda na condição de donos e donas de casa, institui um novo contribuinte e um novo beneficiário da Previdência Social, de acordo com as condiçóes materiais de vida desses e dessas contribuintes.

4 A Lei no 12.470/2011 altera os arts. 21 e 24 da Lei no 8.212/1991 (Lei Orgânica da Seguridade Social), que tratam na seção II da Contribuição dos Segurados Individual e Facultativo. A partir de 2011, a Lei no 12.470 dispôs sobre o Plano de Custeio da Previdência Social, para estabelecer alíquota diferenciada de contribuição para o microempreendedor individual e o segurado facultativo sem renda própria que se dedique exclusivamente ao trabalho doméstico no âmbito de sua residência, desde que pertencente à família de baixa renda. Portanto, a referida Lei passa a tratar de desconto de $11 \%$ para $5 \%$ para os chamados contribuintes facultativos, donos e donas de casa, na condição de baixa renda (Lei 12.470/2011, art. 21, alínea $\left.\mathrm{b}, \$ 4^{\circ}\right)$.

5 Vide Lei no 12.470/2011, art. 1, alínea II-b 
Não restariam dúvidas de que estaríamos diante de uma situação singular em que segmentos das classes subalternas e pauperizadas têm a possibilidade objetiva de ter acesso aos benefícios previdenciários. Para este segmento da classe trabalhadora, historicamente sem direito à cobertura das legislaçóes trabalhista e previdenciária, o acesso à previdência possibilita que tais sujeitos possam lograr uma relativa "segurança social" em situaçóes de doença, invalidez e renda na inatividade, ainda que na condição de um seguro social, de caráter contributivo.

Contudo, a lei expóe um paradoxo, sobretudo, quando analisamos a condição da mulher de baixa renda no mercado de trabalho. Ora, diante da dedicaçáo exclusiva de mulheres e homens ao trabalho doméstico, portanto sem possuir renda oriunda de trabalho remunerado, perguntamo-nos como e sob quais condições essas e esses segurados facultativos, na condição de donas e donos de casa de baixa renda, podem pagar as contribuiçôes à Previdência Social?

Os estudos do Ipea (2010) já revelam que "a cada ano, quando os dados da Pnad/IBGE são divulgados, percebe-se um novo crescimento das famílias 'chefiadas' por mulheres”, razão pela qual, o acesso à renda do trabalho é imperioso; e, mesmo que seus rendimentos não alcancem o teto da renda familiar estabelecido pela Lei no 12.470 (dois salários mínimos), nessa condição de pobreza, é muito pouco provável que as mulheres chefes de família possam se dedicar exclusivamente ao trabalho doméstico como estipulado na legislação, tornando-se, em consequência, desabilitadas para contribuir para a previdência com a alíquota reduzida e, obviamente, comprometendo o direito aos benefícios previdenciários. Como, aliás, já constatado nos estudos de Cordeiro (2014), ${ }^{6}$ quando indica que a principal causa dos indeferimentos nas análises dos pedidos de validação das contribuições, é a existência de renda pessoal no CadÚnico,

Nestes termos, entendemos estar frente a um paradoxo que consiste em:

6 O estudo de Cordeiro (2014), salvo engano, foi pioneiro neste debate e problematizou as conquistas e limites no acesso das mulheres à Previdência Social após a Constituição Federal de 1988, particularmente, analisando a proteção social para donas de casa de baixa renda. 
1) subordinar a condição real de vida das mulheres a uma suposição ideal (que se pretende legal), cancelando, na prática, o que poderia ser uma conquista;

2) essa situação/condição de chefes de família exige que essas mulheres tenham alguma ocupação/trabalho para obter renda e sustentar suas famílias;

3) o fato de não realizarem exclusivamente as tarefas domésticas lhes impede o enquadramento nas exigências da Lei $n^{\circ}$ $12.470 \mathrm{e}$, portanto, de efetivar o direito à previdência;

4) nesse caso, a realidade não contemplaria a existência dessa contribuinte facultativa referida na Lei $\mathrm{n}^{\circ} 12.470$ e se voltaria para um inexpressivo ${ }^{7}$ contingente de mulheres que integram arranjos familiares tradicionais, realizando exclusivamente o trabalho doméstico e possuindo algum tipo de provedor(a);

5) ou, como seria nossa hipótese, a exigência legal determina que tais mulheres assumam os trabalhos mais precários, eventuais, penosos e desprotegidos e clandestinos para serem seguradas da Previdência Social.

Expostas estas questôes, pretendemos fundamentá-las e aprofundá -las numa primeira aproximação à realidade das contribuintes facultativas, cuja imediaticidade do fenômeno nos leva a privilegiar a relação entre mulheres pobres chefes de família e sua vinculação à Previdência Social. Porém, ao que tudo indica, e numa perspectiva de totalidade, subjaz a esta relaçáo tanto a questão da precarização e desproteção do trabalho da mulher quanto a inexistência de unidade entre assistência e previdência no âmbito da seguridade social brasileira.

Este ensaio foi estruturado em duas partes, além desta Introdução e das Consideraçóes Finais. Inicialmente, pontuamos o esgotamento do social-liberalismo à brasileira e as tendências contemporâneas da seguridade social que se inclinam à transição entre a

7 De acordo com o extinto Ministério do Desenvolvimento Social e Combate à Fome (MDS), "o público potencial de donas de casa de baixa renda no país é de 6 milhôes”. (MDS apud IPEA, 2013, p. 20). 
assistencialização da seguridade social e a emergência da proteção social contributiva e focalizada nos de baixa renda; no segundo momento, discorremos sobre elementos que vão norteando a nossa hipótese de trabalho: o acesso à condição de contribuinte facultativa da previdência, supóe que as mulheres donas de casa de baixa renda se submetam a trabalhos (ultra)precários, desprotegidos e clandestinos, para usufruir dos benefícios previdenciários, pela sua condição de chefes de família.

Por se tratar de um estudo em andamento, neste ensaio exporemos algumas sínteses e hipóteses de trabalho que podem contribuir para identificar as contradiçóes entre a conquista do direito das mulheres donas de casa de baixa renda à Previdência Social e a negação do exercício deste direito em face dos impedimentos estruturais e conjunturais relacionados à condição de vida e trabalho das mulheres das classes subalternas e pauperizadas, a quem se destinaria o facultado na Lei 12.470 .

\section{Século XXI: emergência da proteção social contributiva e focalizada}

Numa perspectiva de totalidade, seria insuficiente analisar as legislaçôes e seus critérios de acesso à Previdência Social sem vinculá -los às discussóes das novas morfologias do trabalho frente aos processos de crise do capital e às particularidades da realidade brasileira contemporânea, periférica e dependente, marcada pelas injunçôes neoliberais desde os anos 1990 do século XX.

Isto posto, iniciaremos estas breves reflexóes situando alguns aspectos que se apresentam na trajetória da seguridade social como componente central do tardio Estado social brasileiro e em compasso com as diversas conjunturas históricas, determinadas pela emergência da crise do capital, desde o final dos anos 1970.

O Estado brasileiro, ao longo do século XX, sob tensóes e lutas sociais, construiu as bases sociais e legais que permitiram a criação de um sistema de proteção social, por meio de legislaçóes trabalhistas e sociais cujos destaques ficam por conta dos governos de Getúlio Vargas, a exemplo da CLT, e vão se consolidar com a promulgação da Constituição Federal de 1988, considerada cidadã por garantir, ampliar e 
universalizar direitos sociais e trabalhistas, instituindo, pela primeira vez, um sistema de seguridade social, formado pelas políticas de assistência social, saúde e previdência que, na verdade, desde a sua instituição, não foram amparados por uma dinâmica de unidade, nem tampouco por um orçamento único.

Assim, a partir da segunda metade do século XX o direito à Previdência Social passa a constituir-se em um direito social afeto ao âmbito da seguridade social. Contudo, pode-se considerar que, de 1988 até os dias atuais, a materialização da Previdência Social, como direito social vinculado à seguridade social, vem sendo alvo de intensos ataques por meio de contrarreformas orientadas por princípios do neoliberalismo.

A seguridade social no Brasil está inserida em um amplo e formal sistema de proteçáo social cujos direitos sociais tensionam, contraditoriamente, a disputa pelo fundo público para atender aos interesses do trabalho e do capital. As estratégias neoliberais de ataque à Previdência Social brasileira buscam fragilizá-la e desmontá-la sob o discurso do déficit e das iniquidades no âmbito do que Mota definiu como a cultura da crise. (MOTA, 2008a).

Nesta direção, emergem as estratégias de liberação do fundo público por meio da mercantilização, privatização e assistencialização da seguridade social que, no contexto brasileiro, tem início no pós-1964. De acordo com Mota (2008a), no pós-64, sob a batuta da modernização conservadora, tem início um amplo e perverso processo de mercantilização e privatização das políticas de Previdência Social e saúde, além da educação.

Nestes termos, Mota aponta a expansão seletiva das políticas de seguridade social em que, diferentemente da Constituição de 1988, não se configuram como uma estratégia de universalização da proteção social. Pelo contrário, o que o Estado, sob os preceitos neoliberais vai intensificar é a assistencialização, mercantilização e privatização da proteção social, na medida em que a assistência social se expande, a saúde se mercantiliza e a previdência passa a ser alvo de reformas que dificultam e restringem cada vez mais o acesso aos seus benefícios, também impulsionando a ampliação da previdência privada complementar (fundos de pensão) para os que podem contribuir. 
Em relação à Previdência Social, Mota (2008a, ) destaca que, além da mercantilização, os processos iniciados nos anos 1980 já revelavam a direção dos organismos internacionais acerca do acesso dos segmentos de baixa renda. De acordo com o destacado pela autora, o Banco Interamericano de Desenvolvimento (BID), em relatório sobre a seguridade social na América Latina dizia que se podiam "estabelecer sistemas de previdência para atender à população em idade avançada e de poucos recursos, [...] de tal forma que contribuam para a sua própria seguridade social" (MOTA, 2008a, p. 146). Isto se evidenciou ao longo dos governos do PT, nos anos 2000, conforme já referenciamos ao apresentar a Lei no $12.470 / 2011$.

Partindo para fazer uma consideração sócio-histórica da constituição da seguridade social no Brasil, é mister referenciar um dos aspectos, quiçá o mais relevante nos estudos da Previdência Social, que é o grande paradoxo do Estado social brasileiro (BOSCHETTI, 2008), qual seja: o acesso à Previdência Social se dá pela via do trabalho assalariado, numa sociedade náo salarial ou com frágil assalariamento. (BOSCHETTI, 2008).

Os dados disponíveis revelam o baixo grau de formalização das relações de trabalho, assim como os baixos níveis de rendimento da população sem carteira assinada, expondo os paradoxos na construção das politicas de previdência e assistência social no Brasil (BOSCHETTI, 2008). As pesquisas feministas destacam que, em 2013, havia 40 milhões de pessoas ocupadas em trabalhos informais, significando $42 \%$ da população ocupada no país e, neste universo, $42,7 \%$ eram mulheres que estavam na informalidade. (SOS CORPO, 2015).

Neste sentido, de acordo com Boschetti (2008), "atribui-se à assistência social o papel complementar de proteção limitada às pessoas pobres incapazes de trabalhar". E, por sua vez, à Previdência Social, "a obrigação de trabalhar e a contribuição direta asseguram o direito aos benefícios previdenciários”. (BOSCHETTI, 2008).

Conforme nos revela Mauriel (2012), o quadro institucional que se apresenta no Brasil, no final da primeira década dos anos 2000, sob a batuta dos governos do PT, "apresenta uma estranha aproximação entre combate à pobreza e assistência social”. E como nos diz Mota (2008b, p. 134), "transformando-se [a assistência social] num novo 
fetiche de enfrentamento à desigualdade social, na medida em que se transforma no principal mecanismo de proteção social [...]".

A partir de 2011, com a desaceleração do crescimento econômico, o social-liberalismo dos governos Lula começa a dar sinais de esgotamento, náo mais atendendo interesses da acumulaçáo do capital e fazendo com que o combate à pobreza, tão propagado no contexto dos governos do PT, não seja mais a palavra de ordem, e sim, a austeridade e o corte de benefícios sociais.

$\mathrm{Na}$ conjuntura global, pós-crise de 2007, a segunda década dos anos 2000 aponta o retorno da ortodoxia (ultra)neoliberal, da (ultra) direita e do (ultra)conservadorismo fazendo emergir um caldo cultural necessário para implementar "novos" processos - sob velhas estratégias contrarreformistas, presentes na direção econômica e política dos últimos mandatos dos governos do PT.

Com efeito, o acirramento dos preceitos neoliberais se amplia e vai constituindo novas tendências para o acesso à proteção social no Brasil, apesar dos marcos da "assistencialização" estarem vigentes no âmbito das políticas de seguridade social - a exemplo da obrigação de a população de baixa renda estar inscrita no CadSuas -, como uma espécie de "passaporte" legal-formal para a proteção social, não sob a perspectiva do direito, mas do acesso.

Em outros termos, o Estado brasileiro, desde 2011, em face da informalidade do trabalho e das inúmeras modalidades de precarização do trabalho, parece adequar-se a esta realidade, criando um sem número de novos contribuintes, compatíveis com os novos estatutos do trabalho precarizado.

Nesse sentido, o acesso das donas de casa de baixa renda à Previdência Social se constitui num "avanço" no campo dos direitos sociais, mas ele não prescinde do pressuposto que funda a condição de segurado da previdência: a obrigação de trabalhar, embora suponha na lei que existem mulheres que se dedicam exclusivamente ao trabalho doméstico, mas pertençam a famílias que têm rendimentos de até 2 salários mínimos.

Sem perder a dimensão das contradiçóes, refletimos que a ampliação dos mecanismos de acesso à Previdência Social para os trabalhado- 
res de baixa renda, em um país majoritariamente constituído pela informalidade, que subordina a classe trabalhadora a condiçóes (ultra) precárias, pode conter avanços. Contudo, eles se processam em meio à reprodução das condições de exploração e miséria dos trabalhadores em geral, e, em particular, das mulheres trabalhadoras de baixa renda.

\section{Contribuinte facultativa de baixa renda e trabalho (ultra)precário}

No Brasil, pesquisas do Departamento Intersindical de Estatística e Estudos Socioeconômicos (DIEESE, 2014), revelam que, de maneira geral, as mulheres enfrentam grandes dificuldades no mercado de trabalho, representam mais da metade da população desempregada e, quando ocupadas, percebem menores rendimentos que os homens. E reforçam: o emprego doméstico, ocupação tipicamente feminina, permanece como uma das principais possibilidades de inserção das mulheres, em especial as negras e as mais pobres, com menor escolaridade. ${ }^{8}$

Com efeito, observa-se que a inserção das mulheres no mercado de trabalho não está alterando significativamente a sua relação com o trabalho doméstico, o que redunda, na sobrecarga de trabalho das mulheres (ÁVILA; FERREIRA, 2014). De acordo com o documento Panorama do trabalho das mulheres no Brasil (SOS CORPO, 2015), as mulheres ampliaram sua participação no trabalho remunerado, carregando consigo as tarefas domésticas e de cuidados. Dito de outra forma, em termos do acesso das mulheres ao trabalho remunerado, há importantes avanços no Brasil, mas isso não significa uma transformação da sua relação com o trabalho doméstico, ou afazeres domésticos não remunerados, ainda que desenvolvam as mesmas ocupaçóes que os homens nos mais diversos postos de trabalho. E essa tendência se agrava quando se trata da mulher negra. (SOS CORPO, 2015).

A partir das contemporâneas morfologias do trabalho (ANTUNES, 2013), sob a lógica da acumulação flexível e da reestruturação produtiva, emergiram novos vínculos precários e fragilizados no âmbito do

8 Ver: DIEESE, PED. A inserção da mulher no mercado de trabalho na RMR do Recife, mar./2014. 
trabalho assalariado, criando condiçóes adversas para as classes trabalhadoras. ${ }^{9}$ Estas condiçóes se estendem às mulheres, sobretudo, àquelas vinculadas às classes subalternas que estâo expostas a qualquer tipo de atividade remunerada para obter renda e garantir a sua sobrevivência, de seus filhos e demais dependentes.

$\mathrm{Na}$ realidade brasileira, como já anunciado anteriormente (IPEA, 2010), as mulheres que assumem a manutenção da sua família são chefes de família em arranjos monoparentais femininos - mulheres com filhos -, tornando ainda mais difícil a inserção e a manutenção destas em trabalhos protegidos e deixando evidente a necessidade de obter renda e dar conta, também, do trabalho doméstico não remunerado, como sistematiza a pesquisa do SOS Corpo:

São as mulheres, nesses arranjos monoparentais, as responsáveis pelo provimento de renda e pelo trabalho doméstico, o que prejudica e limita suas possibilidades de inserção no mercado de trabalho ou as submete, sobretudo as mais pobres, a inserirem-se nos postos mais precários e de mais baixos rendimentos. (SOS CORPO, 2015, p. 17).

Nas análises do IPEA (2010, p. 4-7), a maior parte das famílias chefiadas por mulheres é de mães com seus filhos; o que representa mais uma sobrecarga - no sentido da necessidade de recursos e de tempo - num cenário de escassez. Para essas mulheres, a chefia familiar está relacionada não apenas à manutenção econômica, mas também à responsabilidade com a educação e cuidados com os filhos, o que gera intensas jornadas tanto de trabalhos remunerados, como de trabalhos domésticos, não remunerados.

Conforme dados do instituto feminista, em $38,8 \%$ dos domicílios brasileiros, sendo a sua maioria localizada no Nordeste (40\%) e no Norte (38,8\%), observa-se que $46,3 \%$ dos domicílios são chefiados por mulheres brancas e a maioria, $53,6 \%$, por mulheres negras que sobrevivem com até um salário mínimo. (SOS CORPO, 2015).

9 Destaca-se aqui a terceirização e precarização do trabalho, desemprego estrutural, trabalho temporário, parcial, aumento da miserabilidade; todas as prerrogativas da barbárie neoliberal e de sua reestruturação produtiva passaram a caracterizar o cotidiano do mundo do trabalho. (ANTUNES, 2008). 
De acordo com o documento da OIT "Trabalho Decente nas Américas: uma agenda hemisférica - 2006-2015”, publicado em 2006 [...] a região conta com cerca de 551 milhôes de habitantes, dos quais pelo menos 39\% são pobres. Há 239 milhóes de pessoas economicamente ativas (PEA), mais de 23 milhóes (10\%) em desemprego aberto, e em torno de 103 milhóes (43\%) na informalidade. Para a OIT, "pode-se dizer que hoje há um déficit de emprego formal na América Latina que atinge 126 milhóes de trabalhadores, o que representa 53\% da PEA. Esse déficit é mais acentuado no caso das mulheres e dos jovens". (OIT apud DRUCK, 2013, p. 53-60).

O estudo de Ludmila Abílio sobre as revendedoras de cosméticos auxilia nossa argumentação, ao revelar a tendência da informalidade no trabalho de mulheres e apontar aspectos que explicitam o que estamos denominando de (ultra)precarização, como é o caso do trabalho da mulher como uma espécie de "viração". (ABÍLIO, 2014).

A pesquisadora aponta chaves interessantes para se compreender a contraditória "valorização" da mulher no mercado de trabalho. Um primeiro aspecto é a "disponibilidade" deste segmento para ampliar os tempos de trabalho em que ocorre uma indistinção entre tempo de trabalho e tempo de náo trabalho, ou seja, a transformação de todo o seu tempo em potencial tempo de trabalho. (ABÍLIO, 2014).

Com esta assertiva, Abílio (2014) constrói a categoria a plena atividade que nos auxiliou a compreender os processos de exploração e de (ultra)precarização do trabalho das mulheres:

[...] A plena atividade [...] indica sua permeabilidade com outros trabalhos. Trata-se de uma adesão ao trabalho para além do trabalho, ainda que sem formas definidas e de difícil remuneraçâo. Tal adesão foi considerada por uma dupla perspectiva. A primeira, mais imediata, das dificuldades materiais que vêm junto com a precarização do trabalho, ou seja, queda de rendimentos do trabalhador e necessidade de um complemento de renda. A segunda envolve questôes mais complexas, que combinam as motivaçôes subjetivas do trabalho com a ameaça do desemprego. (ABÍLIO, 2014, p. 224, grifos da autora).

Outro aspecto a ser considerado é o fenômeno de feminização do trabalho como expressão da (ultra)precarização que, segundo Antu- 
nes (2008), tanto em países centrais como na América Latina, são marcados por um cenário no qual os níveis de remuneração das mulheres são em média inferiores àqueles recebidos pelos trabalhadores, o mesmo ocorrendo em relação aos direitos sociais e do trabalho, que também são desiguais.

De acordo com Dias (2007), os processos da feminização do trabalho expóem a mulher a contratos temporários, pagamento por hora de trabalho e informalidade em geral. Em termos gerais, a feminização do trabalho passa a se constituir "uma nova modalidade de acumulação do capital em que as mulheres podem estar se configurando como um alvo estratégico, mercadorias eficientes que possuem um baixo custo" (DIAS, 2007, p. 2). E, pela necessidade de sobrevivência, passam a construir estratégias "autônomas", independente da proteção social do Estado, para conciliar a concretização do trabalho produtivo com o trabalho doméstico.

Por certo que a feminização precária do trabalho se revela de diversas formas relacionadas com processos e relaçóes de trabalho que emergem por determinaçáo da reestruturaçáo produtiva. Dentre elas podemos destacar o trabalho em domicílio ou o trabalho produtivo doméstico, que se mescla, segundo Antunes (2008), com o trabalho reprodutivo doméstico não remunerado, aumentando os meios de exploração do contingente feminino.

Ante o exposto, entendemos que a feminização do trabalho analisada sob a referência da plena atividade e como expressão da (ultra) precarização revela as condiçóes sob as quais as mulheres de baixa renda estão realizando trabalhos que lhes geram renda para subsidiar a sua manutenção e de sua família, na condição de chefes de família.

Os estudos de Ludmila Abílio (2014), ao identificar a plena atividade como uma tendência presente no trabalho das mulheres, contribuem para aprofundarmos as pesquisas em torno da condição das donas de casa de baixa renda. Nesta perspectiva, os conceitos de feminização do trabalho e de plena atividade, estudados na sua expressão concreta do cotidiano de mulheres donas de casa de baixa renda, podem se constituir em categorias que permitam examinar a dimensão claro-escuro da nossa hipótese: a de que as mulheres podem estar assumindo a realizaçáo de trabalhos, os mais precários, eventuais, 
penosos e desprotegidos para permanecerem seguradas da Previdência Social na condição de baixa renda.

\section{Consideraçóes finais}

Pelo exposto, estamos afirmando que as mulheres chefes de família das classes subalternas, pauperizadas e expostas a relações informais de trabalho e a trabalhos de "viração", integram o contingente das contribuintes facultativas de baixa renda. Todavia, em face dos critérios da Lei $n^{\circ} 12.470$, elas estariam excluídas da condição de contribuinte facultativa de baixa renda com direito à contribuição reduzida por não atenderem aos critérios da legislação. Endossa nossa suposição o estudo de Cordeiro (2014), segundo o qual 80\% dos indeferimentos de inscrições das donas e donos de casa no INSS se dão pela existência de alguma renda e estão no Nordeste, regiáo "onde se situa um grande número de mulheres em situação de pobreza e que têm se esforçado para contribuir sobre alíquota reduzida”. (p. 299).

O esforço apontado pela pesquisadora contém inúmeros aspectos que devem ser considerados ao problematizar a condição de acesso à renda da mulher dona de casa de baixa renda, conforme já discutimos nos itens anteriores. Neste sentido, a Lei no 12.470 estaria tratando abstratamente a condiçâo de dona de casa, supondo uma exclusividade do trabalho doméstico em relação ao remunerado, fato que a realidade parece contrariar.

As mulheres de baixa renda precisam conciliar a dupla e, às vezes, tripla jornada de trabalho, na qual os afazeres domésticos tomam boa parte do seu tempo e limitam o seu acesso aos trabalhos melhor remunerados e protegidos, a exemplo das atividades remuneradas na área de serviços que absorvem jovens e mulheres, mas exigem uma dedicaçáo média/dia de 12 horas de trabalho - como são exemplos os postos de trabalho em Shopping Center, farmácias e drogarias, supermercados, centros comerciais, hospitais, consultórios e atividades de turismo.

Igualmente, a Lei no 12.470 admite como critério para a contribuição reduzida das mulheres donas de casa, a existência de uma renda familiar resultante de rendimentos de familiares e/ou terceiros (nos termos do CadÚnico). Tudo nos leva a crer que a legislação estaria incorporando, em alguma medida, a concepção tradicional de família, na qual a mulher vive para o lar, não possui renda própria, cuida dos 
dependentes e, sobretudo no Nordeste, está vulnerável aos domínios da cultura machista e patriarcal.

Finalizando as reflexóes apresentadas neste ensaio, cabe retomar as observaçôes de Boschetti (2016, p. 26), no que se refere ao fato de que a Previdência Social deve estar vinculada a um amplo sistema de proteção social, com caráter de universalizaçáo e de atendimento às necessidades dos trabalhadores brasileiros, sobretudo levando em conta as particularidades das condiçóes de vida e trabalho das mulheres das classes subalternas:

[...] organizado, coerente, sistemático, planejado em diversas políticas sociais, financiado pelo fundo público e que garante proteção social por meio de amplos direitos, bens e serviços sociais, nas áreas de emprego, saúde, previdência, habitação, assistência social, educação, transporte, entre outros bens e serviços públicos. Tem como premissa o reconhecimento legal de direitos e a garantia de condições necessárias ao exercício do dever estatal para garanti-los.

Entendemos que o direito à Previdência Social não pode ser compatível com a existência de trabalhos precários e degradantes. Trata-se de uma conquista civilizatória dos trabalhadores brasileiros e que contribui para a sua emancipação política, ainda que nos limites da sociedade do capital.

A defesa do acesso e usufruto dos benefícios da Previdência Social deve estar amparada na existência de uma seguridade social universal que não legitime a exploração e precarização do trabalho de homens e mulheres, mas promova a sua proteção social.

\section{Referências}

ABÍLIO, Ludmila C. Sem maquiagem: o trabalho de um milhão de revendedoras de cosméticos. São Paulo: Boitempo, 2014.

ANTUNES, Ricardo. Século XXI: nova era da precarização estrutural do trabalho? SEMINÁRIO NACIONAL DE SAÚDE MENTAL E TRABALHO. São Paulo, 2008. Disponível em: <http://www.fundacentro. gov.br/Arquivos/sis/EventoPortal/AnexoPalestraEvento/Mesa\%201\%20 -\%20Ricardo\%20Antunes\%20texto.pdf >Acesso em: 10 dez.2016. 
A nova morfologia do trabalho e suas principais tendências. In: ANTUNES, R. (org.). Riqueza e miséria do trabalho no Brasil. São Paulo: Boitempo, 2013. [Coleção Mundo do Trabalho]

ÁVILA, M. Betânia; FERREIRA, Verônica (Orgs). Trabalho remunerado e trabalho doméstico no cotidiano das mulheres. Recife: SOS Corpo; Instituto Feminista para a Democracia, 2014.

BOSCHETTI, Ivanete. Seguridade Social e trabalho: paradoxos na construção das políticas de Previdência e Assistência Social no Brasil. Brasília: Letras Livres; UnB, 2008. Assistência social e trabalho no capitalismo. São Paulo, Cortez, 2016.

BRASIL, IPEA. Instituto de Pesquisas e Estudos Aplicados. PNAD 2009-Primeiras análises: investigando a chefia feminina de família. Brasília, 2010. [Comunicado No 65]

Políticas sociais: acompanhamento e análise, v. 21. Brasília, 2013.

CORDEIRO, Talita T. C. Conquistas e limites no acesso das mulheres à Previdência Social após a Constituiçáo Federal de 1988: análise da proteção social para donas de casa de baixa renda. (Dissertação de Mestrado). Brasília: UnB, 2014.

DIAS, Marly de Jesus, S. Feminização do trabalho $\mathrm{X}$ reestruturação produtiva: a mulher como uma nova modalidade de enriquecimento do capital? JORNADA INTERNACIONAL DE POLÍCAS PÚBLICAS, 3, 2007. Disponível em: <http://www.joinpp.ufma.br/jornadas/joinppIII/html/ Trabalhos/EixoTematicoB/eeab858c197624dc16a8MARLY\%20DE\%20 JESUS\%20S\%C3\%81\%20DIAS.pdf>.Acesso em: 15 dez.2016.

DRUCK, Graça. A precarização social do trabalho no Brasil. In: ANTUNES, Ricardo (Org.). Riqueza e miséria do trabalho no Brasil. São Paulo: Boitempo, 2013. [Coleção Mundo do Trabalho, v. II.]

MAURIEL, Ana P. Pobreza, seguridade e assistência social: desafios da política social brasileira. In: MOTA, Ana E. Desenvolvimentismo e construçáo de hegemonia: crescimento econômico e reprodução da desigualdade. São Paulo: Cortez, 2012.

MOTA, A. E. Cultura da crise e seguridade social: um estudo sobre as tendências da previdência e da assistência social brasileira nos anos 80 e 90. 4. ed. São Paulo: Cortez, 2008a.

O mito da assistência social: ensaios sobre Estado, política e sociedade. 2. ed. São Paulo: Cortez, 2008b.

SOS CORPO. Panorama do trabalho das mulheres no Brasil. In: ÁVILA, Maria B. [et al.] (Orgs.). Desenvolvimento, trabalho e autonomia econômica na perspectiva das mulheres brasileiras. Recife-PE: SOS Corpo, 2015. [PDF] 